\title{
QUEEN'S
UNIVERSITY
BELFAST
}

\section{Perceptions of therapist responses to shame disclosures by clients: A quasi-experimental investigation with non-clinical participants}

Dorahy, M. J., Gorgas, J., Hanna, D., \& Wiingaard, S. U. (2015). Perceptions of therapist responses to shame disclosures by clients: A quasi-experimental investigation with non-clinical participants. Counselling and Psychotherapy Research, 15(1), 58-66. https://doi.org/10.1002/capr.12004

Published in:

Counselling and Psychotherapy Research

Document Version:

Peer reviewed version

Queen's University Belfast - Research Portal:

Link to publication record in Queen's University Belfast Research Portal

\footnotetext{
Publisher rights

(C) 2014 British Association for Counselling and Psychotherapy

This is the peer reviewed version of the following article: Dorahy, M. J., Gorgas, J., Hanna, D. and Wiingaard, S. U. (2015), Perceptions of therapist responses to shame disclosures by clients: A quasi-experimental investigation with non-clinical participants. Counselling and Psychotherapy Research, 15: 58-66. , which has been published in final form at

http://onlinelibrary.wiley.com/doi/10.1002/capr.12004/abstract. This article may be used for non-commercial purposes in accordance with Wiley Terms and Conditions for Self-Archiving.

General rights

Copyright for the publications made accessible via the Queen's University Belfast Research Portal is retained by the author(s) and / or other copyright owners and it is a condition of accessing these publications that users recognise and abide by the legal requirements associated with these rights.
}

Take down policy

The Research Portal is Queen's institutional repository that provides access to Queen's research output. Every effort has been made to ensure that content in the Research Portal does not infringe any person's rights, or applicable UK laws. If you discover content in the Research Portal that you believe breaches copyright or violates any law, please contact openaccess@qub.ac.uk. 
Perceptions of therapist responses to shame disclosures by clients: A quasi-experimental investigation with non-clinical participants

Martin J. Dorahy, Julia Gorgas, Donncha Hanna, and Signe Uldall Wiingaard University of Canterbury, Christchurch, New Zealand

Author Note

Martin J. Dorahy, Department of Psychology, University of Canterbury, Christchurch, New Zealand, The Cannan Institute, Belmont Private Hospital, Brisbane, Australia; Julia Gorgas and Signe Uldall Wiingaard Department of Psychology, University of Canterbury, Christchurch, New Zealand; Donncha Hanna, School of Psychology, The Queen's University of Belfast, Northern Ireland.

Correspondence concerning this article should be addressed to Martin J. Dorahy, Department of Psychology, University of Canterbury, Private Bag 4800, Christchurch, 8140, New Zealand. Email: martin.dorahy@canterbury.ac.nz 


\begin{abstract}
Therapist responses to initial shame disclosure in therapy have received little empirical attention. This study explored different therapeutic responses to shame disclosures in terms of their perceived helpfulness. Responses ranged from complete withdrawal from the feeling (withdrawal) to completely tuning into it (non-withdrawal). Given the tendency of shame to evoke avoidance, participants higher on shame proneness were expected to perceive withdrawal responses to shame as more helpful than non-withdrawal responses. Fifty-five non-clinical participants were assessed for shame-proneness before viewing videos of mock therapy sessions showing clients either disclosing shame (two videos) or shock (control condition). Participants then rated the helpfulness of different therapist responses. The responses differed in the degree they allowed the client to withdraw from their emotions. High shame proneness was associated with rating withdrawal responses to shame as least helpful. Overall, neither the withdrawal response nor the non-withdrawal response were rated as particularly helpful. The therapeutic response which addressed management strategies when shame is initially experienced in therapy was deemed most helpful. Despite the tendency to withdraw from shame feelings, this response is not deemed helpful in therapy. Keywords: Shame, therapeutic interventions, non-clinical
\end{abstract}


Therapist responses to shame disclosures by clients: A quasi-experimental investigation with non-clinical participants

Shame is a commonly experienced self-conscious emotion. In heightened and chronic forms, shame can be severely psychologically debilitating, and growing evidence suggests shame may underlie various clinical presentations (Balcom, Lee, \& Tager, 1995; Capps, 1993, Gilbert \& Procter, 2006; Tangney, Wagner, \& Gramzow, 1992; Tangney, Wagner, Hill-Barlow, Marshall, \& Gramzow, 1996). Unresolved feelings of shame and proneness to shame may act as a mediator for psychological problems (Gilbert, 1998). This has been suggested in the relationship between trauma and psychopathological outcomes, like PTSD and dissociative disorders (e.g., Feiring, Taska, \& Lewis, 2002; Herman, 2011; Kluft, 2007; Lewis, 2008). Shame has further been linked to a range of other psychological problems such as anger, depression, anxiety, and self-injurious behavior (Andrews, Qian, \& Valentine, 2002; Brown, Linehan, Comtois, Murray, \& Chapman, 2009; Hejdenberg \& Andrews, 2011; O’Connor, Berry, \& Weiss, 1999; Tangney, Wagner, Fletcher, \& Gramzow, 1992; Tangney et al., 1996).

It has been suggested that shame is often not identified by therapists or is mistaken for guilt, which may result in ineffective treatment interventions (e.g., Hahn, 2009; Parker \& Thomas, 2009). H. B. Lewis (1971) noted that while feelings of shame encompass the entire self, the experience of guilt is limited to a specific action, event, or behavior. When an individual feels shame, negative judgments are generalized and the whole self is perceived as bad, defective, and inferior. When an individual feels shame, they become self-rather than other-focused, their sense of self is deeply shaken and as a result, they are likely to feel powerless and worthless (Van Vliet, 2008; Tangney, 1996). In Nathanson’s (1992) compass 


\section{THERAPIST RESPONSES TO SHAME DISCLOSURES}

of shame model withdrawal and avoidance responses are proposed as two dominant behavioral coping styles or scripts for feelings of shame. Van Vliet $(2008,2009)$ described a range of avoidance and withdrawal strategies employed to reduce shame, such as denying, ignoring, suppressing, drinking or overeating, isolating the self, as well as avoiding talking about the circumstances producing the painful affect. Thus withdrawal-avoidance of feelings is likely to be a strong motivator and response to shame.

De Hooge, Zeelenberg, and Breugelmans (2010) differentiated between acute shame and shame-proneness (i.e., chronic shame). They proposed that acute shame produces approach behaviors to others when the individual is able and motivated to restore the damaged view of self created by shame. In contrast, when a person experiences chronic shame, it may not be possible to repair the damaged self or the person may feel unable to do so. The individual consequently reacts with withdrawal or avoidance because the motivation is to protect the self from further scrutiny and harm (De Hooge et al., 2010). Thus shameproneness can be maladaptive in the long term and difficult to control (Elison, 2005).

Therapists would typically face clients experiencing chronic rather than acute shame, and behaviors directed at self-protection, like withdrawal and avoidance.

Few studies have explored shame behaviors in the context of therapy (though see Gilbert, 2010) or how to effectively intervene with shame-evoking disclosures. Pineles, Street, and Koenen (2006) have emphasized shame’s significant contribution to symptoms presented in therapy but state that its mere detection can be challenging for therapists as some clients may attempt to conceal any negative self-perceptions. In terms of treatment, Van Vliet (2008) reported that facing and expressing shame were important in successful treatment. Case studies indicate effectiveness of shame-exposure in order to help clients accept and overcome their feelings (Wagner, Rizvi, \& Harned, 2007). The literature does not offer 


\section{THERAPIST RESPONSES TO SHAME DISCLOSURES}

empirically-supported suggestions on appropriate immediate intervention strategies for clients disclosing shame during therapy.

If withdrawal-type behaviors to shame occur in therapy (e.g., withdrawing from discussion of shame), the therapist is challenged to respond to the client in such a way as to reduce such withdrawal, while simultaneously 1) encouraging the client to express their true thoughts and emotions, and 2) reducing their fear of being judged. While it has been suggested that shame be directly addressed (Pineles et al., 2006), this approach may not be initially effective if the client automatically reacts by withdrawing from the situation and the therapist (external withdrawal) or their own thoughts and feelings (internal withdrawal). Provided that internal and external withdrawal are dominant behavioral strategies for shame when evoked in therapy, it might be expected that clients feeling shame would not want their therapist to probe further into the feeling because it would reduce their ability to withdraw from shame. Alternatively, the safety of the therapeutic environment and the desire to be understood and supported by the therapist might buffer against withdrawal when shame is evoked. These two opposing motivations might operate in the client's inner world creating uncertainty about immediate interventions when shame is experienced in therapy.

This study sought to explore how helpful people considered different therapist responses to be after they saw mock clients engage in shame disclosures in the therapeutic setting. It was designed to assess participants' helpfulness ratings of therapist responses to expressed feelings of shame. Furthermore, this research sought to shed light on potentially helpful versus less helpful responses a therapist can make to reduce withdrawal while keeping the client engaged (e.g., discussing initially how shame feelings are managed rather than felt). Short video clips were developed for this study and shown to participants. The video clips showed mock clients disclosing either shame or shock (control condition) to their therapist. Five possible responses the therapist might make to the client were shown ranging 


\section{THERAPIST RESPONSES TO SHAME DISCLOSURES}

from allowing the client to withdraw from their feelings completely (withdrawal response) to asking the client to stay completely with the emotion (non-withdrawal response). It was expected that participants would rate the withdrawal response as most helpful and the nonwithdrawal response as least helpful, and this was predicted especially to be the case for those with more shame-proneness.

\section{Method}

\section{Participants}

Fifty-five university students participated in the study (ten males and 45 females) in return for a $\$ 10$ food or petrol voucher. Participants were 18 to 50 years old $(M=22.17, S D=$ 5.11) and recruited by email sent to all first and third year psychology students. The email outlined the purpose of the study, the general procedure and how to participate. In addition, advertisements were distributed on information boards and in student washrooms on campus. The sample was made up of European and Mäori New Zealanders.

\section{Materials}

Participants were administered demographic questions (e.g., age, sex, history of psychological difficulties), and a measure of trait shame (the Experience of Shame Scale; Andrews et al., 2002). In addition, participants were given a computer-presented shame and shock disclosure observation task.

The Experience of Shame Scale (ESS; Andrews et al., 2002) consists of 25 items that measure characterological shame, behavioral shame, and bodily shame over the past 12 months. Characterological shame assesses shame related to personal habits, manner with others, view of self, and personal ability. Behavioral shame assesses shame in response to making a mistake, saying something stupid, and failing in a competitive situation. Bodily shame assesses shame related to personal appearance. Participants rate each question on a 4point scale, ranging from 1 (not at all) to 4 (very much). Total scores range from 25 to 100 


\section{THERAPIST RESPONSES TO SHAME DISCLOSURES}

with higher scores indicating more shame experiences. Internal consistency has been reported at $r=.92$ (Andrews et al., 2002) and in the current study it was $r=.94$. The ESS was utilized in this study to assess shame-proneness.

\section{Therapy Video Clips}

The therapy video clips showed mock therapy sessions that were based on three vignettes written by the research team. Two vignettes (Shame $1 \&$ Shame 2) involved clients disclosing to their therapist feelings of shame, while the third vignette showed a client disclosing feelings of shock. The content of each vignette was drawn from clinical material as well as theoretical and empirical considerations. Cognitive, affective, visceral, and behavioral components of shame and shock were integrated into the vignettes (Van Vliet, 2009). As outlined by Gilbert, Pehl, and Allan (1994), shame involves a perception of the self as the object of scorn, disgust, ridicule, and humiliation. The individual who experiences shame feels paralyzed and helpless, inferior and small compared to others and often displays involuntary body responses such as blushing, tears, and gaze avoidance. The feeling of shame is often accompanied by a wish to hide and withdraw from others, and their focus is entirely on the self. The vignettes incorporated these aspects of shame and their equivalents for the shock script. Participants were unaware they were observing mock therapy sessions.

Each vignette was acted out by professional actors. Six 'client' video clips were produced (Shame 1 with male and female 'client'; Shame 2 with male and female 'client'; Shock with male and female 'client'). The same female actor in all six video clips portrayed the therapist. The videos were presented to participants in a predetermined random order. If the first shame video (randomly Shame 1 or Shame 2) was shown with the male 'client,' the second shame clip would be shown with the female 'client' and vice versa. Thus, every participant saw a male and female disclosing shame. To counterbalance order effects and gender effects, the shock video was randomly presented before, between, or following the 


\section{THERAPIST RESPONSES TO SHAME DISCLOSURES}

two shame videos and with either the female or the male 'client.' The videos slightly varied in length from two minutes to four minutes. The start of all videos showed the 'therapist' and 'client,' and then zoomed into the upper body and face of the client. One shame video described a non-specified experience at a party and feeling exposed and vulnerable (see appendix for full script). The other shame video described feeling shame as a result of being in therapy. The shock video described a non-specified event in which the person felt shocked, speechless and startled (see Appendix).

\section{Therapist Response Clips}

For each shame and the shock vignette, a set of five different therapist responses was developed by the research team. Each response contained two parts: the first part (i.e., passive intervention) aimed at validating the emotions (e.g., 'this must be a very tough experience for you...'), the second part (i.e., active intervention) was designed to allow the client different degrees of withdrawal from their expressed feelings (e.g., "could you tell me more about what this feeling is like for you'). In each response set (i.e., five therapeutic responses), one response encouraged the client to talk more about their feelings of shame (or shock) and therefore did not allow any withdrawal (non-withdrawal response) whereas another response offered complete withdrawal to the client by suggesting they talk about their feelings another time (withdrawal response). Examples include: "It must be very hard to feel this way about yourself. I know this may be difficult, but can you try staying with these feelings and tell me what this is like for you?” (Non-withdrawal) and “This sounds very distressing for you to discuss. Perhaps it might be best if we spoke about it when you are feeling better” (Withdrawal).

The other three responses in each set focused on thoughts around the feelings, similar past experiences the client may have had and how the client managed or attempted to reduce the emotional experience. These responses provided some degree of withdrawal. Examples 


\section{THERAPIST RESPONSES TO SHAME DISCLOSURES}

include: "It must be so difficult to think this way about yourself. I'm wondering if you can tell me more about the thoughts you have about yourself when you feel like this” (Thoughts); “This must be such a tough experience for you. Does it trigger any memories of similar past experiences?” (Past experience); and “This must be difficult. Perhaps you can tell me some of the things you do to try and keep these feelings and thoughts at bay?” (Management strategies). Participants were asked to put themselves in the position of the 'client' while watching the videos and rate how helpful they believed the therapist response would be to the client on a 10-point scale ranging from 1 (very unhelpful) to 10 (very helpful). Thus for the withdrawal responses given by the therapist, higher scores indicated advocating more withdrawal, while for the non-withdrawal therapist interventions, higher scores indicated staying with the affect state. To experimentally control for possible gender disclosure effects, responses to the shame 1 and shame 2 videos were merged to give a single score. Thus for each of the five therapeutic interventions/response types, there were single scores for shame and shock.

\section{Structure of therapist responses}

Both the passive and active intervention parts of the therapeutic responses in the two shame vignettes differed slightly but highly resembled each other in meaning. To avoid any effects resulting from the particular combination of any two parts, four response sets were produced whereby each passive intervention part was matched with each of the active intervention parts. These sets formed the basis for the therapist response video clips. To avoid order effects, a shame video was randomly followed by one of the four response clips. Moreover, the response types (e.g., non-withdrawal, withdrawal) were presented in random order following each client disclosure video. The therapist response clips varied in length from seven to fourteen seconds. The therapist alone was shown in the videos offerings the 5 interventions. 


\section{THERAPIST RESPONSES TO SHAME DISCLOSURES}

\section{Procedure}

Participants were invited to take part in a research study investigating the helpfulness of different therapist responses to clients expressing emotions during a therapy session. On arrival at the laboratory, they read an information sheet and signed a consent form. All materials were presented on a programmed website. After stating demographics, participants proceeded to complete the ESS. Participants then viewed the videos. No indications were given that the therapy sessions were mock. After each video, they saw the therapist provide five potential responses to the client's material. Participants rated each response directly after it was given. Participants read the following instruction before each therapist intervention: "If you were the client, how helpful would it be if your therapist said the following.” Each therapist response was shown in a video clip as well as written out above the rating scale. After participants had seen all three client videos and given their response to each intervention, they were debriefed about the study and any further questions were addressed. All procedures were approved by the University Human Ethics Committee.

\section{Analysis}

The present study employed a repeated measures design with the 'emotion' independent variable having two levels (shame and shock) and the 'therapist response' independent variable having five levels (withdrawal, non-withdrawal, thoughts, past experiences, management). The dependent variable was helpfulness ratings of therapist responses ranging from 1 (very unhelpful) to 10 (very helpful). Furthermore, simple linear regression was utilized to determine if shame proneness predicted helpful responses. All analyses were conducted in IBM SPSS 19.

\section{Results}

One participant was removed as an outlier as they uniformly rated all responses as 10 therefore the sample size was reduced to 54 for all analyses. 


\section{THERAPIST RESPONSES TO SHAME DISCLOSURES}

A 2X5 Within-Subjects ANOVA was conducted on the response ratings with the independent variables of emotion (shame v shock) and therapist's responses (withdrawal, non-withdrawal, thoughts, past experiences, management). There was a significant main effect of emotion, $F(1,53)=10.55 ; p=.002 ; h_{p}{ }^{2}=.17$, with shock emotion videos $(5.60)$ returning higher mean helpfulness ratings than the shame videos (5.10). There was also a significant main effect of therapist's response, $F(4,212)=31.86 ; p<.001 ; h_{p}{ }^{2}=.38$. The withdrawal response was rated as significantly lower or less helpful than all other 4 possible responses. Both non-withdrawal and thought responses were seen as significantly lower or less helpful than the management response (see table 1 for descriptive statistics). There was no significant interaction.

Insert Table 1 about here

Although the shock videos tended to demonstrate a slightly higher mean than the shame videos for helpfulness ratings there was only a significant difference in mean ratings for the non-withdrawal responses, $t(53)=3.62 ; p=.001 ; d=0.53$, as illustrated in figure 1 . Participants suggested the non-withdrawal response was more helpful when exploring shock compared to shame when first disclosed in therapy.

Insert Figure 1 about here

To explore ratings for the shame videos in more detail a Within-Subjects ANOVA was conducted on the perceived helpfulness response ratings with the independent variable being the five therapist's responses for the shame videos only. There was a significant main effect of therapist's response, $F(4,212)=28.06 ; p<.001 ; h_{p}{ }^{2}=.35$. The withdrawal response 


\section{THERAPIST RESPONSES TO SHAME DISCLOSURES}

was rated the least helpful of possible responses and had a significantly lower mean rating than all 4 of the other responses (see table 1 for descriptive statistics). The non-withdrawal response was seen as the next least helpful response and had significantly lower mean ratings than past experiences or management responses. The thought response was rated as significantly less helpful than the management response. As can be seen from Table 1 the management response was seen as the most helpful response (significantly higher mean ratings than withdrawal, non-withdrawal and thought responses) followed by the past experience response (significantly higher mean ratings than withdrawal and non-withdrawal responses).

Simple Linear regression was carried out to determine the influence of shame proneness as measured by the ESS $(M=57.02$; $S D=15.07)$ on helpfulness ratings for each on the therapist's responses. A statistically significant model for shame proneness on the withdrawal response $(F(1,52)=9.62 ; p=.003)$ was discovered. Adjusted $R^{2}$ indicated that $14 \%(\beta=-.40 ; t=3.01 ; p=.003)$ of the variance in the rating of helpfulness for the therapist's withdrawal response could be explained by shame proneness; greater shame proneness predicted a lower helpfulness rating. Shame proneness was not a significant predictor of helpfulness ratings on any of the other therapist's responses.

\section{Discussion}

This study is one of the first to experimentally simulate specific interventions to shame disclosures in therapy. It examined how non-clinical individuals perceived different discrete therapist interventions after initial shame disclosures by a client. When asked how they would like the therapist to respond if they were the client disclosing a shame- (or shock) inducing event, participants generally rated the helpfulness of each intervention as similar for shock and shame disclosures, with the exception of the non-withdrawal intervention. Here participants felt it was more helpful to stay directly with the feeling of shock than shame. 


\section{THERAPIST RESPONSES TO SHAME DISCLOSURES}

Participants overall suggested that interventions allowing complete withdrawal were less helpful. Shame prone participants in particular indicated that such an intervention to initial shame disclosures was less helpful. However, participants overall also stated that the therapist asking clients to stay with the emotion (non-withdrawal) is less helpful for shame than shock. Thus, participants overall, and those with high shame proneness, did not feel withdrawal was helpful nor did participants overall believe that staying focused on the shame feeling was particularly helpful when it was disclosed in therapy. Seemingly an intervention between these two poles was considered more helpful, with management of the feeling rated most helpful. Thus, an intervention that allowed clients some contact with the affect of shame when disclosed in therapy while also providing some potential degree of efficacy over the affect (i.e., how it is managed) was deemed most helpful.

Results do not support the predicted withdrawal pattern following the shame video. Participants as a group, and particularly those with higher levels of shame-proneness, affirmed that therapeutic interventions to shame which allowed withdrawal were least helpful. Yet, at least outside therapy, withdrawal is often used as a response to shame (Nathanson, 1992). These findings have potential clinical implications. They suggest that while shame prone individuals might have a tendency to withdraw from shame outside therapy, these same people recognize that in therapy, it is beneficial not to withdraw from facing this emotion. The tendency to rate withdrawal responses as less helpful may indicate an underlying belief that negative feelings about the self associated with shame can be overcome, which would result in more approach-type behaviors as asserted by De Hooge et al. (2010). The therapeutic context specifically may also provide hope that shame can be overcome, which could activate varying degrees of approach behavior in high shame prone clients, despite their fear of shame-activation. Another possible interpretation is that the shame expressed in the videos was perceived more as an acute experience for the participants 


\section{THERAPIST RESPONSES TO SHAME DISCLOSURES}

themselves rather than a chronic and persistent feeling (De Hooge et al., 2010). In this case, and in line with De Hooge and colleagues' work, withdrawal would be a less likely response. Thus, the endorsement to not withdraw from shame in therapy may be based on acute rather than chronic feelings.

The findings seem to indicate that shame prone clients may believe that withdrawal from the emotion of shame in therapy is ineffective and not therapeutic. This could consequently suggest some willingness to work with the therapist despite likely feelings of discomfort when faced with one's shame. However, our results further indicate that it may not resonate well to deeply probe into the feeling when shame is first disclosed. Instead, the therapist can potentially help the client to stay engaged and avoid reactive withdrawal by focusing on how they manage shame. This dilutes the intensity of shame, but does not facilitate withdrawal. Such a strategy links with previous research that suggests shame is resolved over time by clients changing their negative self-perceptions from being global and stable to become more specific and unstable (Van Vliet, 2009). Shame management may constitute a first step in this direction.

Limitations. Rating the helpfulness of therapist responses to the shame disclosures of another in a video is not identical to experiencing the utility of such responses to one's own disclosures of shame in actual therapy. Despite this restriction, the methodology was expected to provide an estimate of people's tendencies to withdraw following exposure to shame in the context of therapy and it allowed control over what participants were exposed to.

Future research should use a similar methodology to explore withdrawal behaviors to shame in individuals with major psychological disorders. Their feelings of shame are likely to be much more severe and ingrained than in student samples. Moreover, it would be interesting to test whether a clinical sample shows any strong intervention preferences to 


\section{THERAPIST RESPONSES TO SHAME DISCLOSURES}

shame disclosures. Based on Van Vliet's (2008) findings with regards to the processes involved in overcoming shame and rebuilding one’s self-perceptions, reducing shame withdrawal behaviors is followed by connecting with others as well as accepting and expressing one's emotions and thoughts. Comparing withdrawal patterns of a clinical sample with the findings obtained from this university sample may show that non-clinical individuals faced with shame are somewhat further along the road to recovery. Rather than engaging in entirely different coping patterns, the latter group may be at a more advanced stage of processing their shame, perhaps because shame is less engrained into their personality. Clinical patients, on the other hand, may be less aware of the source and the meaning of their negative self-perceptions, making shame a more chronic and debilitating experience managed with withdrawal and avoidance rather than approach behaviors. A further direction for future work is how the therapeutic relationship influences the client's perception of a therapist's response to shame disclosures, and the degree it mediates what is considered helpful.

The current findings suggest withdrawal and non-withdrawal (staying directly with felt affect) interventions to initial shame disclosures in therapy were not deemed helpful. Interventions which enquire about management strategies for shame and therefore allow a more diluted connection with the affect were deemed most helpful. Future research findings including the results obtained from this study may determine that in order to effectively intervene with clients imbued with chronic shame, the therapist should carefully match their response to the degree to which the client can acknowledge and tolerate the painful affect of shame. 


\section{THERAPIST RESPONSES TO SHAME DISCLOSURES}

References

Andrews, B., Qian, M., \& Valentine, J. D. (2002). Predicting depressive symptoms with a new measure of shame: The experience of shame scale. British Journal of Clinical Psychology, 41, 29-42. doi:10.1348/014466502163778

Balcom, D., Lee, R. G., Tager, J. (1995). The systemic treatment of shame in couples. Journal of Marital and Family Therapy, 27, 55-65. doi:10.1111/j.17520606.1995.tb00138.x

Brown, M. Z., Linehan, M. M., Comtois, K. A., Murray, A., \& Chapman, A. L. (2009). Shame as a prospective predictor of self-inflicted injury in borderline personality disorder: A multi-modal analysis. Behaviour Research and Therapy, 47, 815-822. doi:10.1016/j.brat.2009.06.008

Capps, D. (1993). The depleted self: sin in a narcissistic age. Minneapolis: Fortress.

De Hooge, I. E., Zeelenberg, M., \& Breugelmans, S. M. (2010). Restore and protect motivations following shame. Cognition and Emotion, 24, 111-127. doi:10.1080/02699930802584466

Elison, J. (2005). Shame and guilt: a hundred years of apples and oranges. New Ideas in Psychology, 23, 5-32. doi:10.1016/j.newideapsych.2005.07.001

Feiring, C., Taska, L., \& Lewis, M. (2002). Adjustment following sexual abuse discovery: The role of shame and attributional style. Developmental Psychology, 38, 79-92. doi: 10.1037/0012-1649.38.1.79

Gilbert, P. (1998). What is shame? Some core issues and controversies. In P. Gilbert, \& B. Andrews (Eds.), Shame: Interpersonal behavior, psychopathology, and culture (pp. 3-38). Oxford: Oxford University Press.

Gilbert, P. (2010). Compassion focused therapy: Distinctive features. Routledge. 


\section{THERAPIST RESPONSES TO SHAME DISCLOSURES}

Gilbert, P., Pehl, J., \& Allan, S. (1994). The phenomenology of shame and guilt: An empirical investigation. Journal of Medical Psychology, 67, 23-26. doi:10.1111/j.20448341.1994.tb01768.x

Gilbert, P., \& Procter, S. (2006). Compassionate mind training for people with high shame and self-criticism: Overview and pilot study of a group therapy approach. Clinical Psychology and Psychotherapy, 13, 353-379. Doi: 10.1002/cpp.507.

Hahn, W. K. (2009). Shame. In W. O’Donohue \& S. R. Graybar (Eds.), Handbook of contemporary psychotherapy: Towards an improved understanding of effective psychotherapy. Los Angeles: Sage.

Hejdenberg, J., \& Andrews, B. (2011). The relationship between shame and differ types of anger: A theory-based investigation. Personality and Individual Differences, 50, 1278-1282. Doi:10.1016/j.paid.2011.02.024

Herman, J. L (2011). PTSD as a shame disorder. In R. L. Dearing \& J. P. Tangney (Eds.), Shame in the therapy hour. Washington, DC: American Psychological Association. doi:10.1037/12326-000

Kluft, R. P. (2007). Applications of innate affect theory to the understanding and treatment of dissociative identity disorder. In E. Vermetten, M. J. Dorahy, \& D. Spiegel (Eds.), Traumatic Dissociation: Neurobiology and Treatment (pp.301-316). Washington, DC: American Psychiatric Publishing.

Lewis, H. B. (1971). Shame and Guilt in Neurosis. New York: International Universities Press.

Lewis, M. (2008). Self-conscious emotions: embarrassment, pride, shame, and guilt. In M. Lewis, J. M. Haviland-Jones, \& L. Feldman Barrett (Eds.), Handbook of emotions (pp. 742-756). New York: the Guilford Press.

Nathanson, D. L. (1992). Shame and Pride. New York: Norton. 


\section{THERAPIST RESPONSES TO SHAME DISCLOSURES}

O’Connor, L. E., Berry, J. W., \& Weiss, J. (1999). Interpersonal guilt, shame, and psychological problems. Journal of Social and Clinical Psychology, 18(2), 181-203. doi:10.1521/jscp.1999.18.2.181

Parker, S. \& Thomas, R. (2009). Psychological differences in shame vs. guilt: Implications for mental health counselors. Journal of Mental Health Counseling, 31, 213-224. doi: 2009-11267-003

Pineles, S. L., Street, A. E., \& Koenen, K. C. (2006). The differential relationships of shame-proneness and guilt-proneness to psychological and somatisation symptoms. Journal of Social and Clinical Psychology, 25, 688-704. doi:10.1521/jscp.2006.25.6.688

Tangney, J. P. (1996): Conceptual \& methodological issues in the assessment of shame and guilt. Behaviour Research and Therapy, 34, 741-754. doi:10.1016/0005-7967(96)000344

Tangney, J. P., Wagner, P., Fletcher, C., \& Gramzow, R. (1992). Shamed into anger? The relation of shame and guilt to anger and self-reported aggression. Journal of Personality and Social Psychology, 62, 669-675. doi:10.1037/0022-3514.62.4.669

Tangney, J. P., Wagner, P. E., \& Gramzow, R. (1992). Proneness to shame, guilt, and psychopathology. Journal of Abnormal Psychology, 101, 469-478. doi:10.1037/0021843X.101.3.469

Tangney, J. P., Wagner, P. E., Hill-Barlow, D., Marshall, D. E., Gramzow, R. (1996). Relation of shame and guilt to constructive versus destructive responses to anger across the lifespan. Journal of Personality and Social Psychology, 70, 797-809. doi:10.1037/0022-3514.70.4.797

Van Vliet, J. K. (2008). Shame and resilience in adulthood: a grounded theory study. Journal of Counselling Psychology, 55, 233-245. doi:10.1037/0022-0167.55.2.233 


\section{THERAPIST RESPONSES TO SHAME DISCLOSURES}

Van Vliet, K. J. (2009). The role of attributions in the process of overcoming shame: a qualitative analysis. Psychology and Psychotherapy, 82, 137-152. doi:10.1348/147608308X389391

Wagner, A. W., Rizvi, S. L., \& Harned, M. S. (2007). Applications of Dialectical Behaviour Therapy to the treatment of complex trauma-related problems: When one case formulation does not fit all. Journal of Traumatic Stress, 20, 391-400. doi:10.1002/jts.20268 
Appendix

\section{Shame vignette 1}

Therapist: At the end of our last session you started to touch upon an incident that you seemed uncomfortable remembering and you said it was hard to talk about (Behavioural shame).

Client: (eye gaze shift from therapist (looks away), look downs, talking slowly, not really wanted to remember or talk about it. Arms crossed, shoulders hunched. Body turned slightly away from the therapist): Yeah, I...I...it's on my mind a lot, ahh...but I've never spoken to anyone about it, I'm not sure I can, it... it makes me feel so useless, so inferior, like I'm not worth anything to anyone. Even thinking about it makes me want to hide away. I'm afraid that if I was ever to tell anyone they wouldn't want to know me anymore, they'd see the me that I see and think I was hideous. The night it happened I'd been feeling good. I'd finally agreed to go to a small house party with a friend and I felt anxious because of how shy I am, but also felt good that I'd taken the step to go. Then everything changed, all eyes in room turned to me and I could feel their mocking stares. I felt paralysed, my mind went blank and I felt everyones' gaze burning a hole in me, I could hardly breathe and I felt my face going red, I could hear people laughing and sneering and looking down at me. I could feel their contempt for me and I just wanted to get out, I wanted the floor to open up and swallow me. I couldn't look at anyone. I felt helpless to do anything.

T: How does that make you feel about yourself.

C: I hate myself, I hate everything about me, there's nothing I like and nothing anyone else could like. The way I look, the way I behaviour, I'm repulsive, how could anyone like this (in depressed, sombre tone). I'm so awkward with other people, I would rather avoid everyone because I just feel so uncomfortable, like I'm on a lower level to everyone else and can never be equal or feel that I'm the same. I always feel useless and there's nothing I can do about it. This is me: defective, flawed, rotten to the core.

Shame vignette 2

T: So, tell me more about what this is like for you.

C: Well, ...,

(client looks away, finds it difficult to talk, moves around on the chair, uncomfortable)

C: ... I feel exposed. ... like you can see right through me and recognize what kind of person I really am... that you can see the badness and weakness. I so often feel this way. I despise that you see me like this, that you make me feel this way. I come here to get better and you just make me feel worse. This isn't working. I'm just useless, I can't be helped. I just want to go away and not come back...

(voice somber, flat, eyes focused on ground).

T: Go on

C: I want to hide... I hate it when you see me like this, like, ... loathing me. I hate myself, my face. I am not worth it ... that's just who I am. Like whatever I say is not good enough, funny enough, interesting enough. Nobody is as stupid, clumsy, useless as I am ... I just don't want to say or do anything anymore ... I want to get out of my skin and I can't! This makes me so angry... There's something so deeply wrong with me. How can anything ever change that? This feeling sticks to me, follows me everywhere ... I can't escape it ... and everyone must notice that I am not like them, sooner or later. Even meeting new people, all I can think is when are they going to start seeing the real me and lose interest, and show how disgusting they think I am? I feel stuck ... Stuck with something, an image, that I don't want. But there is nothing, nothing (!!!) I can do!

\section{Surprise/shock vignette}

T: So, tell me how you experienced this.

C: (bubbly, eye-contact, shaking head, arms up, gesturing)

C: I heard it and saw it and couldn't believe it, my eyes nearly popped out, I couldn't believe someone could do that. I was startled and speechless. It really shocked me and still does just thinking of it. It's nearly as if it's not real, it's incredible, staggering and appalling all at the same time. 
T: It seemed to have a real impact on you

I just couldn't believe someone would do this. It was totally unexpected and I didn't know what to say or how to react. I was astounded!

There were all these questions racing through my head, like, how could this even have happened, you know? No one saw it coming. And then, crap, what do I do now? I felt a bit lost, taken off-guard. I was amazed and also unprepared for it, you know? It came out of the blue, and like...like it struck me out of nowhere. My stomach turned a bit, and I couldn't really believe it at the time, I still can't. I was stunned, like I couldn't really move at that moment. 
Table 1: Descriptive statistics for helpfulness ratings for each of the therapist responses for the shame and shock videos

\begin{tabular}{|l|l|c|c|c|}
\hline \multirow{2}{*}{$\begin{array}{c}\text { Therapists' } \\
\text { response }\end{array}$} & \multicolumn{1}{|c|}{ Video } & Mean & Standard & Range \\
\hline Withdrawal & Shame & 3.22 & 1.79 & $1-8$ \\
\cline { 2 - 5 } & Shock & 3.72 & 2.00 & $1-9$ \\
\hline \multirow{2}{*}{ won- } & Shame & 4.86 & 1.77 & $2-9$ \\
\hline \multirow{2}{*}{ Thoughts } & Shock & 5.93 & 2.30 & $1-10$ \\
\cline { 2 - 5 } & Shame & 5.19 & 1.80 & $1.5-8$ \\
\cline { 2 - 5 } & Shock & 5.67 & 2.35 & $1-10$ \\
\hline \multirow{2}{*}{ Past experiences } & Shame & 5.79 & 1.87 & $1-9.5$ \\
\cline { 2 - 5 } & Shock & 6.11 & 2.13 & $1-10$ \\
\hline \multirow{2}{*}{ Management } & Shame & 6.46 & 2.02 & $1-9$ \\
\cline { 2 - 5 } & Shock & 6.59 & 1.95 & $3-10$ \\
& & & & \\
\hline
\end{tabular}




\section{THERAPIST RESPONSES TO SHAME DISCLOSURES}

Figure 1: Mean helpfulness rating scores for shame and shock videos for each of the therapist's responses from 1 (very unhelpful) to 10 (very helpful)

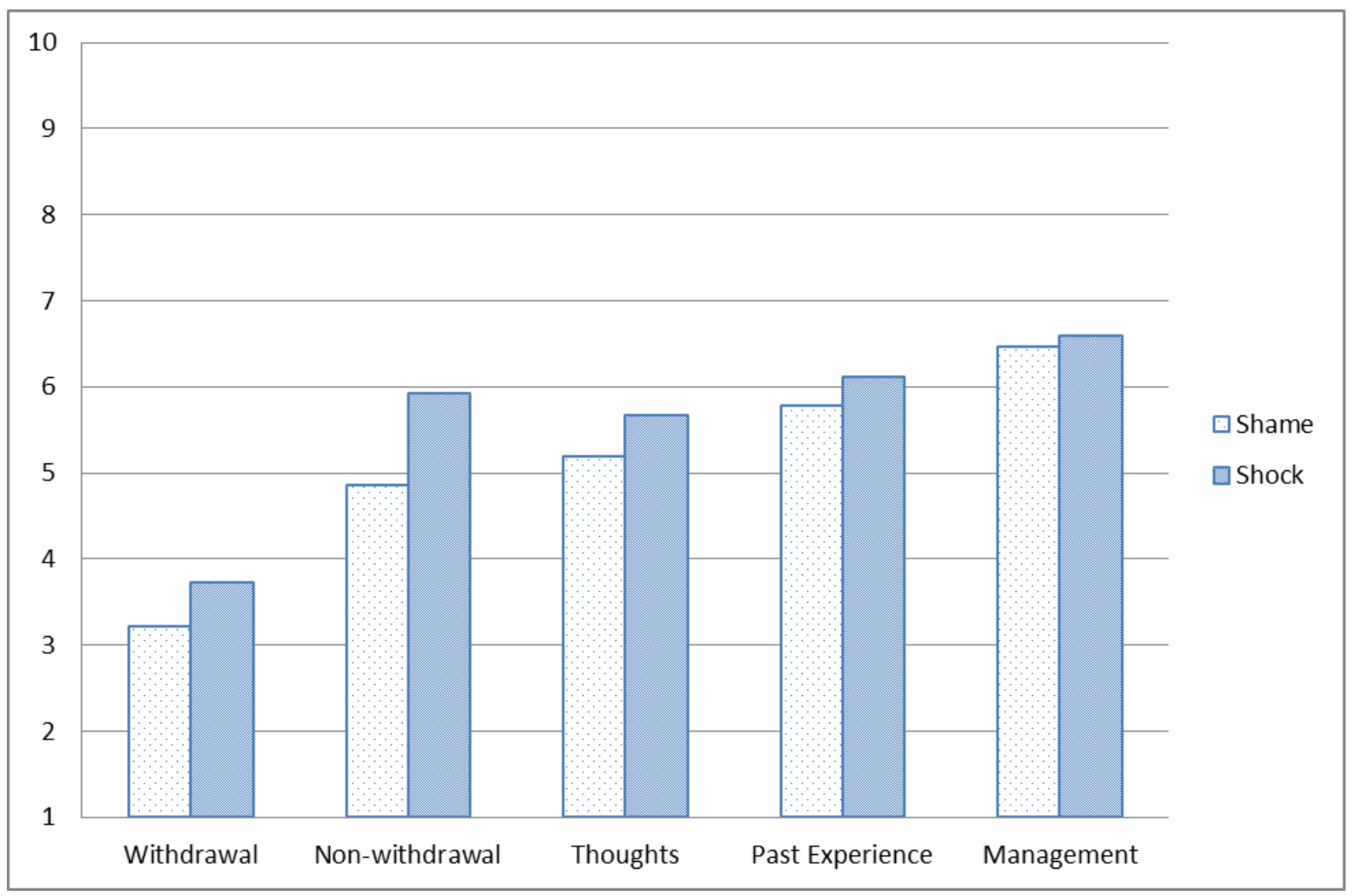

